\title{
Synthesis, optical and thermal behaviour of palladium(II) complexes with 4-(4-alkoxy-2-hydroxybenzylideneamino)azobenzene
}

\author{
BOON-TECK HENG ${ }^{\mathrm{a}}$, GUAN-YEOW YEAP ${ }^{\mathrm{a}, *}$ and DAISUKE TAKEUCHI ${ }^{\mathrm{b}}$ \\ ${ }^{a}$ Liquid Crystal Research Laboratory, School of Chemical Sciences, Universiti Sains Malaysia, \\ 11800 Minden, Penang, Malaysia \\ ${ }^{\mathrm{b}}$ Chemical Resources Laboratory (Mailbox R1-03), Tokyo Institute of Technology, 4259 Nagatsuta, \\ Midori-ku, Yokohama, 226-8503, Japan \\ e-mail: gyyeap@usm.my
}

MS received 6 April 2013; revised 18 August 2013; accepted 21 August 2013

\begin{abstract}
A series of new Pd(II) complexes derived from the reaction of palladium acetate with 4-(4-alkoxy2-hydroxybenzylideneamino)azobenzene having the flexible terminal chain of $\mathrm{OC}_{n} \mathrm{H}_{2 n+1}$, in which $n$ are even numbers ranging from 8 to 16, has been successfully synthesized. The physical measurement and spectroscopic techniques (FTIR and ${ }^{1} \mathrm{H}-\mathrm{NMR}$ ) reveal that the $\mathrm{Pd}(\mathrm{II})$ complexes possess the $\mathrm{Pd}-\mathrm{N}$ and $\mathrm{Pd}-\mathrm{O}$ coordination modes in which the central $\mathrm{Pd}(\mathrm{II})$ adopts square-planar geometry. The observation under the polarized light shows that all the ligands and $\mathrm{Pd}(\mathrm{II})$ complexes exhibit enantiotropic mesophases. The ligands with $n$-octyloxy and $n$-decyloxy flexible chains exhibit the nematic (N) and smectic A (SmA) phases whilst the Pd(II) complexes show exclusive SmA phase. The SmA phase observed in $\mathrm{Pd}(\mathrm{II})$ complexes can be supported by the presence of focal conic fan-shaped texture with the presence of curved lines which are prominent during the cooling process. On the other hand, the comparison studies show that $\mathrm{Pd}(\mathrm{II})$ complexes possess exceptional higher phase transition temperatures as compared to the corresponding $\mathrm{Cu}$ (II) and $\mathrm{Ni}$ (II) complexes.
\end{abstract}

Keywords. $\mathrm{Pd}(\mathrm{II})$ complexes; smectic A; nematic; ${ }^{1} \mathrm{H}-\mathrm{NMR}$; $\mathrm{Cu}(\mathrm{II})$ complexes.

\section{Introduction}

Metallomesogens are commonly referred to the coordination compounds which include the complexes containing mesogenic or non-mesogenic ligands, salt of organic acids or certain organometallic compounds possessing $s, p, d$ and $f$ block metals. ${ }^{1}$ The last ten years have seen a steady increase in the interest towards these metallomesogens and the recognition of their potential as advanced materials. ${ }^{2}$ One of the reasons making these metallomesogen so essential in the technological advancement is the ultimate shapes associated with various geometries of the central metal atom or ion ranging from square planar, folder square, lantern, pyramidal and octahedral geometrical shapes. ${ }^{3,4}$ From the chemical and physical viewpoints, the central metal ions can enhance the richness in oxidation state, colour and magnetism. ${ }^{5}$

Among these materials, the azo-based polymeric liquid crystals or metallomesogens containing uncomplexed azo moieties has been given more attention. In

*For correspondence general, the metallomesogens containing the uncomplexed azo moieties are capable of changing the molecular shape by the reversible cis-trans isomerization under the influence of UV or photoirradiation. These materials are useful particularly in the development of information recording system such as high-density optical data storage, optical switching, display and nonlinear optics. ${ }^{6,7}$ Another interesting feature of these compounds lies on its potential to form rod-like molecules leading to the liquid crystalline properties. ${ }^{8}$

Rezvani and co-workers had earlier reported the synthesis and liquid crystalline properties of some metallomesogens containing isomerizable azo moieties wherein the metal ion such as $\mathrm{Cu}(\mathrm{II}), \mathrm{Ni}(\mathrm{II})$ and $\mathrm{VO}(\mathrm{IV})$ are widely used in formulating the novel metallomesogenic system. ${ }^{9,10}$ In 2002, Nandiraju and co-workers reported the influence of metal ion on the mesomorphic properties of the ligands. ${ }^{11}$ Similar studies had been carried out by Suste and co-workers. ${ }^{5}$ In spite of these studies, the influence of the metal on the mesophase and correlation of the structure with the anisotropic properties of metallomesogens are still subject to further investigation.

Recently, we have reported the synthesis and liquid crystalline character of $\mathrm{Cu}$ (II) and $\mathrm{Ni}$ (II) complexes 
with ligands derived from azobenzene-cored Schiff base. ${ }^{12,13}$ Thus, in this work, we report the synthesis and liquid crystalline properties of new bis[4-(4-alkoxy-2hydroxybenzylideneamino)azobenzene]palladium(II) homologous compounds (scheme 1). Besides, the differences among the ultimate complexes in terms of their optical and thermal behaviour are also studied and reported.
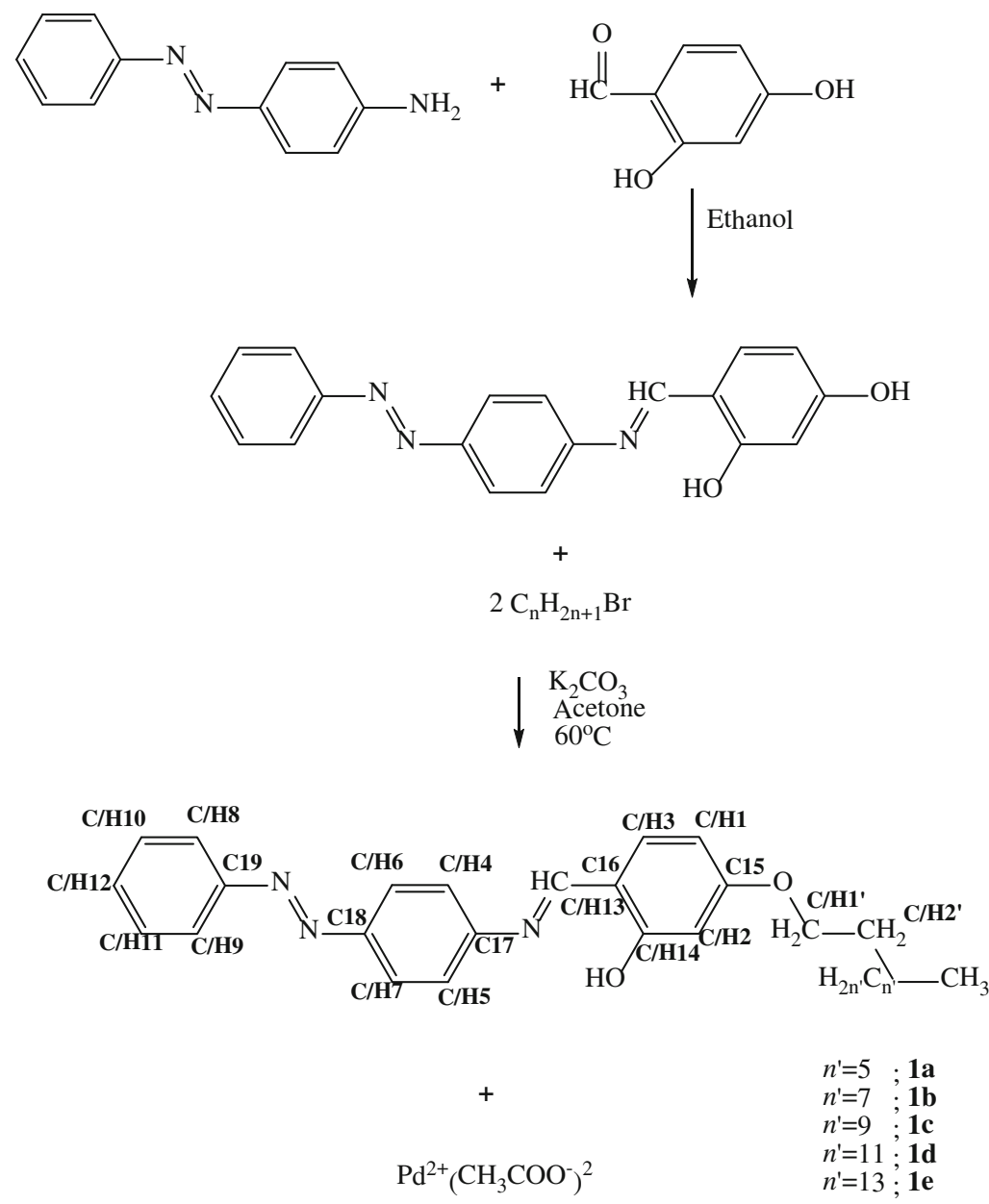

Ethanol

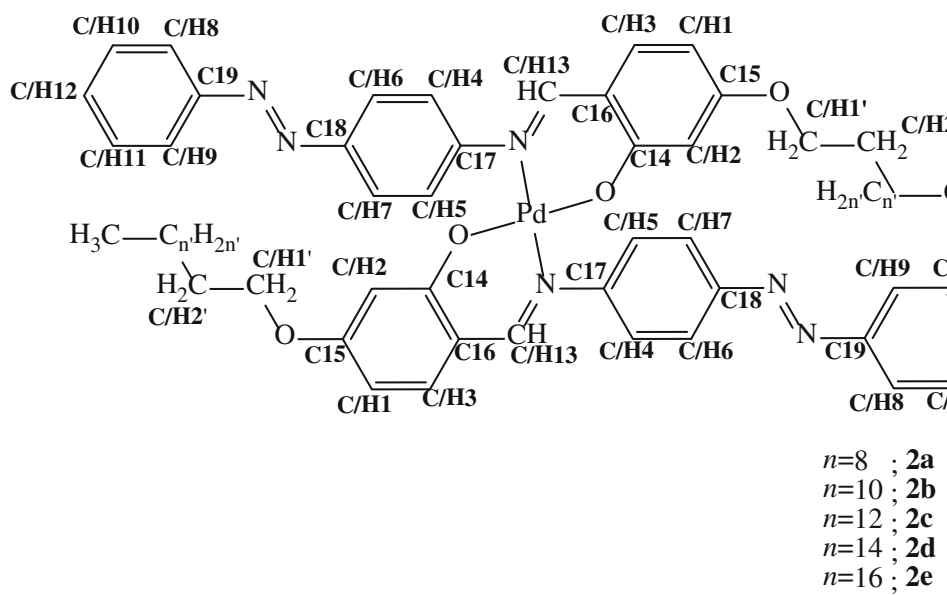

Scheme 1. Synthetic routes toward formation of ligands $\mathbf{1 a}-\mathbf{1 e}$ and $\mathrm{Pd}(\mathrm{II})$ complexes $\mathbf{2 a}-\mathbf{2 e}$. 


\section{Experimental}

\subsection{Materials}

Potassium carbonate was purchased from Systerm while 2,4-dihydroxybenzaldehyde was obtained from Acros Organic. 1-Bromooctane, 1-bromodecane, 1-bromododecane, 1-bromotetradecane, 1-bromohexadecane and palladium(II) acetate were purchased from Merck whereas 4-aminoazobenzene was purchased from Aldrich-Chemical. All reagents mentioned above are used without further purification.

\subsection{Physical measurements}

The ${ }^{1} \mathrm{H}-\mathrm{NMR}$ spectra were obtained by using Brucker Avance $400 \mathrm{MHz}$ ultrashield spectrometers equipped with ultrashield magnet. Deuterated chloroform $\left(\mathrm{CDCl}_{3}\right)$ and dimethysulphoxide (DMSO- $\left.\mathrm{d}_{6}\right)$ were used as solvent and TMS as internal standard. The FTIR spectra were recorded using a Perkin Elmer 2000-FTIR spectrophotometer in the frequency range $4000-400 \mathrm{~cm}^{-1}$ with sample prepared in $\mathrm{KBr}$ disc. Elemental $(\mathrm{C}, \mathrm{H}$ and $\mathrm{N})$ analysis were carried out using a Perkin Elmer 2400 LS Series CHNS/O analyzer. The phase transition temperatures and enthalpy values were measured by using a Seiko DSC6200R calorimeter with the heating and cooling rate of $\pm 5^{\circ} \mathrm{C}$. The optical observations were made with a Carl Zeiss Axioskop 40 polarizing microscope equipped with a Linkam LTS 350 hot stage and TMS94 temperature controller. The samples studied by optical microscope were prepared in thin film sandwiched between glass slide and cover.

\subsection{Synthesis of 4-(4-alkoxy-2-hydroxybenzylideneamino) azobenzene, 1a-1e}

The synthesis of 4-(4-alkoxy-2-hydroxybenzylideneamino)azobenzene, 1a-1e follows the method similar to that reported earlier. ${ }^{12,13}$

\subsection{Synthesis of the Pd(II) complexes $2 a-2 e$}

An ethanolic solution (10 mL) of palladium(II) acetate $(1.0 \mathrm{mmol})$ was added drop-wise to a hot ethanolic solution $(50 \mathrm{~mL})$ of ligands $1(1.0 \mathrm{mmol})$ in round bottom flask. The mixture solution was refluxed for $6 \mathrm{~h}$ and then cooled to room temperature. The dark green precipitate was collected by filtration and recrystallized from ethanol.

2a: Dark green, yield 82\%. Elemental analysis/\%: Found $\mathrm{C}$ 67.59, $\mathrm{H}$ 6.42, N 8.60; calculated $\left(\mathrm{C}_{54} \mathrm{H}_{60} \mathrm{~N}_{6} \mathrm{O}_{4} \mathrm{Pd}\right), \quad \mathrm{C}$ 67.36, $\mathrm{H}$ 6.23, $\mathrm{N}$ 8.73. IR
$(\mathrm{KBr}) v_{\max } / \mathrm{cm}^{-1}: 1206$ (C-O ether), 1309 (C-O phenolic), $1470(\mathrm{~N}=\mathrm{N}), 1587 \quad(\mathrm{C}=\mathrm{C}), 1605(\mathrm{C}=\mathrm{N})$, 2921-2850 (C-H alkyl). ${ }^{1} \mathrm{H}$ NMR (400 MHz, $\mathrm{CDCl}_{3}$ ), $\delta(\mathrm{ppm}): 6.17(\mathrm{dd}, \mathrm{H} 1, J=12 \mathrm{~Hz}), 5.55(\mathrm{~s}, \mathrm{H} 2)$, 7.08 (d, H3, J = 12 Hz), 7.48-7.62 (m, H4, H5, H10, H11, H12), 8.02 (d, H6, H7, J = 8 Hz), 7.97 (dd, $\mathrm{H} 8, \mathrm{H} 9, J=4 \mathrm{~Hz}$ ), 7.66 (s, H13), 3.67 (t, H1', $J=$ $4 \mathrm{~Hz}$ ), 1.20-1.64 (m, H2'-H7'), 0.89 (t, H8', $J=8 \mathrm{~Hz}$ ). ${ }^{13} \mathrm{C}$ NMR (75 MHz, $\mathrm{CDCl}_{3}$ ), $\delta$ (ppm): 107.70 (C1), 102.33 (C2), 135.91 (C3), 123.83 (C4,C5), 125.04 (C6,C7), 123.88 (C8, C9), 129.61 (C10,C11), 131.41 (C12), 153.10 (C13), 161.10 (C14), 165.87 (C15), 114.90 (C16), 152.57 (C17), 151.12 (C18), 151.35 (C19), 68.22 (C1'), 32.31-23.10 ( C2'-C7'), 14.53 (C8).

2b: Dark green, yield $81 \%$. Elemental analysis/\%: Found $\mathrm{C}$ 68.56, $\mathrm{H}$ 6.92, $\mathrm{N}$ 8.14; calculated $\left(\mathrm{C}_{58} \mathrm{H}_{68} \mathrm{~N}_{6} \mathrm{O}_{4} \mathrm{Pd}\right), \quad \mathrm{C}$ 68.37, $\mathrm{H}$ 6.67, $\mathrm{N}$ 8.25. IR $(\mathrm{KBr}) v_{\max } / \mathrm{cm}^{-1}: 1206(\mathrm{C}-\mathrm{O}$ ether$), 1310(\mathrm{C}-\mathrm{O}$ phenolic), $1469(\mathrm{~N}=\mathrm{N}), 1588 \quad(\mathrm{C}=\mathrm{C}), 1606(\mathrm{C}=\mathrm{N})$, 2923-2852 (C-H alkyl). ${ }^{1} \mathrm{H}$ NMR $\left(400 \mathrm{MHz}, \mathrm{CDCl}_{3}\right)$, $\delta(\mathrm{ppm}): 6.17$ (dd, H1, $J=12 \mathrm{~Hz}), 5.56(\mathrm{~s}, \mathrm{H} 2), 7.09$ (d, H3, $J=12 \mathrm{~Hz}$ ), 7.49-7.63 (m, H4, H5, H10, H11, H12), 8.02 (d, H6, H7, J = 8 Hz), 7.96 (dd, H8, H9, $J=4 \mathrm{~Hz}), 7.65(\mathrm{~s}, \mathrm{H} 13), 3.67\left(\mathrm{t}, \mathrm{H} 1^{\prime}, J=4 \mathrm{~Hz}\right)$, 1.19-1.63 (m, H2'-H9'), 0.89 (t, H10', $J=8 \mathrm{~Hz}$ ). ${ }^{13} \mathrm{C}$ NMR (75 MHz, $\left.\mathrm{CDCl}_{3}\right), \delta(\mathrm{ppm}): 107.70(\mathrm{C} 1)$, 102.34 (C2), 135.97 (C3), 123.82 (C4,C5), 125.09 (C6,C7), 123.87 (C8, C9), 129.61 (C10,C11), 131.40 (C12), 153.15 (C13), 161.08 (C14), 165.88 (C15), 114.91 (C16), 152.57 (C17), 151.13 (C18), 151.34 (C19), 68.22 (C1'), 32.31-23.10 (C2'-C7'), 14.54 (C8).

2c: Dark green, yield 83\%. Elemental analysis/\%: Found $\mathrm{C}$ 69.53, $\mathrm{H}$ 7.31, N 7.72; calculated $\left(\mathrm{C}_{62} \mathrm{H}_{76} \mathrm{~N}_{6} \mathrm{O}_{4} \mathrm{Pd}\right), \mathrm{C}$ 69.27, $\mathrm{H}$ 7.07, $\mathrm{N}$ 7.82. IR $(\mathrm{KBr}) v_{\max } / \mathrm{cm}^{-1}$ : $1206(\mathrm{C}-\mathrm{O}$ ether $), 1310(\mathrm{C}-\mathrm{O}$ phenolic), $1469(\mathrm{~N}=\mathrm{N}), 1587(\mathrm{C}=\mathrm{C}), 1606(\mathrm{C}=\mathrm{N})$, 2924-2852 (C-H alkyl). ${ }^{1} \mathrm{H}$ NMR (400 MHz, $\mathrm{CDCl}_{3}$ ), $\delta$ (ppm): 6.17 (dd, H1, $J=12 \mathrm{~Hz}), 5.56$ (s, H2), 7.09 (d, H3, $J=12 \mathrm{~Hz}$ ), 7.49-7.63 (m, H4, H5, H10, H11, H12), 8.02 (d, H6, H7, $J=8$ Hz), 7.97 (dd, H8, H9, $J=4 \mathrm{~Hz}), 7.66(\mathrm{~s}, \mathrm{H} 13), 3.67\left(\mathrm{t}, \mathrm{H} 1^{\prime}, J=4 \mathrm{~Hz}\right)$, 1.19-1.63 (m, H2'-H11'), 0.90 (t, H12', $J=8 \mathrm{~Hz}$ ). ${ }^{13} \mathrm{C}$ NMR $\left(75 \mathrm{MHz}, \mathrm{CDCl}_{3}\right), \delta(\mathrm{ppm}): 107.70(\mathrm{C} 1)$, 102.34 (C2), 135.95 (C3), 123.82 (C4,C5), 125.04 (C6,C7), 123.88 (C8,C9), 129.61 (C10,C11), 131.42 (C12), 153.14 (C13), 161.10 (C14), 165.87 (C15), 114.90 (C16), 152.58 (C17), 151.13 (C18), 151.35 (C19), 68.22 (C1'), 32.31-23.10 ( C2'-C7'), 14.53 (C8).

2d: Dark green, yield 79\%. Elemental analysis/\%: Found C 70.31, H 7.67, N 7.38; calculated 
$\left(\mathrm{C}_{66} \mathrm{H}_{84} \mathrm{~N}_{6} \mathrm{O}_{4} \mathrm{Pd}\right), \quad \mathrm{C} 70.10, \quad \mathrm{H}$ 7.43, $\mathrm{N}$ 7.43. IR $(\mathrm{KBr}) v_{\max } / \mathrm{cm}^{-1}$ : 1206 (C-O ether), 1309 (C-O phenolic), $1470(\mathrm{~N}=\mathrm{N}), 1589(\mathrm{C}=\mathrm{C}), 1605(\mathrm{C}=\mathrm{N})$, 2922-2851 (C-H alkyl). ${ }^{1} \mathrm{H}$ NMR (400 MHz, $\mathrm{CDCl}_{3}$ ), $\delta(\mathrm{ppm}): 6.53$ (dd, H1, $J=12 \mathrm{~Hz}), 5.56(\mathrm{~s}, \mathrm{H} 2), 7.09$ (d, H3, $J=12 \mathrm{~Hz}), 7.49-7.62$ (m, H4, H5, H10, H11, H12), 8.02 (d, H6, H7, $J=8 \mathrm{~Hz}$ ), 7.96 (dd, H8, H9, $J=4 \mathrm{~Hz}), 7.66(\mathrm{~s}, \mathrm{H} 13), 3.67\left(\mathrm{t}, \mathrm{H1}{ }^{\prime}, J=4 \mathrm{~Hz}\right)$, 1.20-1.63 (m, H2'-H13'), 0.91 (t, H14', $J=8 \mathrm{~Hz}$ ). ${ }^{13} \mathrm{C}$ NMR $\left(75 \mathrm{MHz}, \mathrm{CDCl}_{3}\right), \delta(\mathrm{ppm}): 107.72(\mathrm{C} 1)$, 102.35 (C2), 135.92 (C3), 123.81 (C4,C5), 125.05 (C6,C7), 123.88 (C8,C9), 129.63 (C10,C11), 131.41 (C12), 153.12 (C13), 161.09 (C14), 165.89 (C15), 114.92 (C16), 152.58 (C17), 151.12 (C18), 151.33 (C19), 68.21 (C1'), 32.31-23.09 (C2'-C7'), 14.54 (C8).

2e: Dark green, yield 85\%. Elemental analysis/\%: Found $\mathrm{C}$ 71.08, $\mathrm{H}$ 8.05, N 6.95; calculated $\left(\mathrm{C}_{70} \mathrm{H}_{92} \mathrm{~N}_{6} \mathrm{O}_{4} \mathrm{Pd}\right), \mathrm{C} 70.83, \mathrm{H}$ 7.75, $\mathrm{N}$ 7.08. IR $(\mathrm{KBr}) v_{\max } / \mathrm{cm}^{-1}: 1206$ (C-O ether), 1309 (C-O phenolic), $1469(\mathrm{~N}=\mathrm{N}), 1589 \quad(\mathrm{C}=\mathrm{C}), 1605 \quad(\mathrm{C}=\mathrm{N})$, 2920-2851 (C-H alkyl). ${ }^{1} \mathrm{H}$ NMR $\left(400 \mathrm{MHz}, \mathrm{CDCl}_{3}\right)$, $\delta$ (ppm): $6.16(\mathrm{dd}, \mathrm{H} 1, J=12 \mathrm{~Hz}), 5.56(\mathrm{~s}, \mathrm{H} 2), 7.09$ (d, H3, $J=12 \mathrm{~Hz}), 7.49-7.62$ (m, H4, H5, H10, H11, H12), 8.02 (d, H6, H7, J = 8 Hz), 7.97 (dd, H8, H9, $J=4 \mathrm{~Hz}), 7.66(\mathrm{~s}, \mathrm{H} 13), 3.67\left(\mathrm{t}, \mathrm{H} 1^{\prime}, J=4 \mathrm{~Hz}\right)$, 1.20-1.64 (m, H2'-H15'), 0.89 (t, H16,$J=8 \mathrm{~Hz}) .{ }^{13} \mathrm{C}$ NMR (75 MHz, $\mathrm{CDCl}_{3}$ ), $\delta(\mathrm{ppm}): 107.71(\mathrm{C} 1), 102.33$ (C2), 135.91 (C3), 123.83 (C4,C5), 125.05 (C6,C7), 123.87 (C8,C9), 129.62 (C10,C11), 131.41 (C12), 153.10 (C13), 161.10 (C14), 165.87 (C15), 114.92 (C16), 152.56 (C17), 151.12 (C18), 151.35 (C19), 68.20 (C1'), 32.31-23.10 ( C2'-C7'), 14.53 (C8).

\section{Results and discussion}

\subsection{Synthesis}

Ligands 1a-1e were obtained from the condensation between aromatic amine and 2,4-dihydroxybenzaldehyde wherein the imine thus obtained was alkylated by various bromoalkane $\left(\mathrm{C}_{n} \mathrm{H}_{2 n+1} \mathrm{Br}\right.$; where $\left.n=8-16\right)$ via the Williamson etherification. The reactions between $\mathbf{1 a}$ and 1e with $\mathrm{Pd}(\mathrm{II})$ acetate in stoichiometric ratio have led to the formation of Pd(II) complexes $\mathbf{2 a}-\mathbf{2} \mathbf{e}$ as dark green solids. The structure elucidation for compounds 1a-1e and 2a-2e were carried out by FT-IR, ${ }^{1} \mathrm{H}-\mathrm{NMR}$ and elemental analysis. The physical properties of the compounds thus obtained are summarized in experimental section. These data show that the empirical formula are in accordance with all the complexes $\mathbf{2 a - 2 e}$ of which the ratio of $\mathrm{Pd}(\mathrm{II})$ to ligands is $1: 2$.
From the FTIR data of ligands 1a-1e and corresponding Pd(II) complexes $\mathbf{2 a - 2 e}$, it can be observed that the broad band assignable to the $\mathrm{O}-\mathrm{H}$ stretching in the free ligands disappears upon complexation with $\mathrm{Pd}(\mathrm{II})$ indicating that the $\mathrm{OH}$ group is deprotonated. As such, the ligand is coordinated to the metal ion via the anionic $\mathrm{O}^{-} \cdot{ }^{1,9,10,14}$ Furthermore, the coordination of $\mathrm{O}$ to $\mathrm{Pd}(\mathrm{II})$ ion is further supported by the stretching vibration of phenolic $\mathrm{C}-\mathrm{O}$ which has shifted to a higher frequency at $1309-1310 \mathrm{~cm}^{-1}$ as compared to $1280-1285 \mathrm{~cm}^{-1}$ in uncoordinated ligands. ${ }^{15,16} \mathrm{Com}-$ paring the stretching frequency of azomethine $\mathrm{C}=\mathrm{N}$ in the free ligand $\left(1624-1625 \mathrm{~cm}^{-1}\right)$ and that in $\operatorname{Pd}(\mathrm{II})$ complexes $\left(1605-1606 \mathrm{~cm}^{-1}\right)$ suggests the coordination of non-bonding electron on $\mathrm{N}$ atom to central $\mathrm{Pd}(\mathrm{II})$ ion. This observation can be ascribed to the reduction of double bond character of the $\mathrm{C}=\mathrm{N}$ bond and it is in agreement with the results obtained from other analogous complexes. ${ }^{5,9-11,14,17,18}$ Besides, a weak band at $1471-1473 \mathrm{~cm}^{-1}$ indicates the stretching frequency of azolinkages of $\mathrm{N}=\mathrm{N} .{ }^{19}$ Since this band is not shifted upon complex formation, therefore, the coordination of the $\mathrm{N}$ atom from the azo-linkages to $\mathrm{Pd}(\mathrm{II})$ ion can be ruled out. All of these observations support the formation of $\mathrm{Pd}-\mathrm{O}$ and $\mathrm{Pd}-\mathrm{N}$ coordination modes in which the ratio of $\mathrm{Pd}(\mathrm{II})$ to ligands is $1: 2$.

The investigation by the ${ }^{1} \mathrm{H}-\mathrm{NMR}$ chemical shifts $(\delta)$ shows that the signals for $\mathrm{H} 1$ and $\mathrm{H} 2(\delta$ 6.51$6.55 \mathrm{ppm}), \mathrm{H} 3$ ( $\delta 7.30-7.33 \mathrm{ppm})$ and H13 ( $\delta$ 8.62$8.63 \mathrm{ppm})$ in uncoordinated ligands $\mathbf{1 a}-\mathbf{1 e}$ are shifted upfield upon complexation. The upfield shift of proton signals shows the increase of shielding effect which can be explained by the nature of the molecular structures of $\mathbf{2 a}-\mathbf{2 e}$ wherein the $\mathrm{Pd}(\mathrm{II})$ ion is stabilized by $\mathrm{Pd}-\mathrm{O}$ and $\mathrm{Pd}-\mathrm{N}$ coordination modes. The stabilization has further been enhanced through the existence of back bonding from $\mathrm{Pd}(\mathrm{II})$ ion to the conjugated system consisting of $\mathrm{H} 1, \mathrm{H} 2, \mathrm{H} 3$ and $\mathrm{H} 13 .{ }^{20}$ Besides, the overlapping of chemical shifts for proton $\mathrm{H} 1$ and $\mathrm{H} 2$ in uncoordinated ligands is not observed in $\mathrm{Pd}(\mathrm{II})$ complexes. These two protons have shifted to upper field giving rise to two separate peaks. The large upfield shift in the chemical shift of azomethine proton $\mathrm{H} 13$ has further substantiated the coordination of $\mathrm{N}$ atom from the ligands to the central $\mathrm{Pd}(\mathrm{II})$ ion. ${ }^{17,18,20} \mathrm{In}$ addition, the absence of a singlet at $\delta=13.60 \mathrm{ppm}$ indicates that $\mathrm{OH}$ group is deprotonated prior to form new coordination mode of $\mathrm{Pd}-\mathrm{O}$. The ${ }^{13} \mathrm{C}-\mathrm{NMR}$ chemical shifts $(\delta)$ for azomethine carbon $(\mathrm{C} 13)$ and $\mathrm{OH}$ group carbon of $\mathrm{C} 14$ also support the presence of new coordination mode of $\mathrm{Pd}-\mathrm{O}$ whereby the chemical shift of $\mathrm{C} 13$ and $\mathrm{C} 14$ at respective $\delta=162.38-$ $162.40 \mathrm{ppm}$ and $\delta=164.48-164.56 \mathrm{ppm}$ were shifted 
Table 1. Phase transition temperature $\left({ }^{\circ} \mathrm{C}\right)$ and associated enthalpy $\left(\mathrm{kJ} \mathrm{mol}^{-1}\right)$ given in parenthesis of ligands $\mathbf{1 a}-\mathbf{1 d}$.

\begin{tabular}{|c|c|c|c|c|c|c|c|c|c|}
\hline Ligands & & $\mathrm{Cr}_{1}$ & & $\mathrm{Cr}_{2}$ & $\mathrm{SmA}$ & & $\mathrm{N}$ & & \\
\hline \multirow[t]{2}{*}{$1 \mathbf{a}$} & Heating & $\bullet$ & $74.2(5.4)$ & - $109.7(30.5)$ & & $164.3^{\mathrm{a}}$ & - & $176.5^{\mathrm{a}}$ & \\
\hline & Cooling & - & $76.1(-23.5)$ & & & $161.1^{\mathrm{a}}$ & & $173.9^{\mathrm{a}}$ & \\
\hline \multirow[t]{2}{*}{ 1b } & Heating & $\bullet$ & $99.6(7.7)$ & $107.1(27.7)$ & & $166.9^{\mathrm{a}}$ & $\bullet$ & $168.5(3.3)$ & \\
\hline & Cooling & - & $80.7(-31.7)$ & & & $159.4^{\mathrm{a}}$ & - & $162.6^{\mathrm{a}}$ & \\
\hline \multirow[t]{2}{*}{$1 c$} & Heating & - & & $106.8(36.3)$ & - & & & $165.1(3.2)$ & - \\
\hline & Cooling & - & & $96.1(-34.3)$ & - & & & $168.2(-3.6)$ & $\bullet$ \\
\hline \multirow[t]{2}{*}{ 1d } & Heating & - & & $110.3(64.2)$ & - & & & $167.9(6.5)$ & - \\
\hline & Cooling & - & & $91.5(-66.1)$ & - & & & $164.6(-6.0)$ & • \\
\hline
\end{tabular}

Cr, crystal; N, nematic; Sm A, smectic A; I, isotropic

aDenotes transition temperature derived from unresolved peaks

Dot means the presence of the phase

to $153.10-153.15 \mathrm{ppm}$ and $161.08-161.10 \mathrm{ppm}$ upon complex formation.

The central $\mathrm{Pd}(\mathrm{II})$ ion in respective complexes $\mathbf{2 a}-$ 2e is stabilized by the two equivalent ligands in which the palladium ion possesses square planar geometry. This can be supported by the ${ }^{1} \mathrm{H}-\mathrm{NMR}$ spectra in which no peak broadening was detected. This observation is in agreement with that reported by Blackburn and coworkers in which they found that the tetrahedral geometry of metal complexes caused the peaks broadening whereas the square planar analogues prevented the peak broadening. ${ }^{19}$ In addition, the square planar geometries of $\mathrm{Pd}(\mathrm{II})$ in complexes $\mathbf{2 a - 2 e}$ can be further evident by their common stereochemistry as reported by Hudson and co-workers. ${ }^{21}$

\subsection{Liquid crystalline properties}

The liquid-crystalline properties of ligands 1a-1e with their corresponding Pd(II) complexes have been studied by polarizing optical microscope (POM) equipped

Table 2. Phase transition temperature $\left({ }^{\circ} \mathrm{C}\right)$ for complexes 2a-2e.

\begin{tabular}{lllrlll}
\hline Complexes & & Cr & & SmA & & I \\
\hline 2a & Heating & $\bullet$ & 256.2 & $\bullet$ & 261.9 & $\bullet$ \\
& Cooling & $\bullet$ & 158.6 & $\bullet$ & 260.8 & $\bullet$ \\
2b & Heating & $\bullet$ & 247.4 & $\bullet$ & 257.4 & $\bullet$ \\
& Cooling & $\bullet$ & 186.5 & $\bullet$ & 251.4 & $\bullet$ \\
2c & Heating & $\bullet$ & 224.5 & $\bullet$ & 249.2 & $\bullet$ \\
& Cooling & $\bullet$ & 74.3 & $\bullet$ & 238.5 & $\bullet$ \\
2d & Heating & $\bullet$ & 215.6 & $\bullet$ & 236.6 & $\bullet$ \\
& Cooling & $\bullet$ & 84.1 & $\bullet$ & 228.9 & $\bullet$ \\
& Heating & $\bullet$ & 204.9 & $\bullet$ & 223.4 & $\bullet$ \\
& Cooling & $\bullet$ & 83.3 & $\bullet$ & 215.4 & $\bullet$ \\
\hline
\end{tabular}

Dot means the presence of the phase with a heating and cooling hot stage and their enthalpy values are obtained by differential scanning calometry (DSC). The respective phase transition temperatures and enthalpy values for ligands $\mathbf{1 a - 1 e}$ and $\mathrm{Pd}(\mathrm{II})$ complexes $\mathbf{2 a - 2 e}$ are illustrated in tables 1 and 2. All ligands with their corresponding $\mathrm{Pd}(\mathrm{II})$ complexes exhibit enantiotropic mesophase. The homologous ligands with $n=8$ (1a) and $n=10$ (1) show the schlieren and the focal conic fan-shaped textures characteristic of nematic $(\mathrm{N})$ and smectic $\mathrm{A}(\mathrm{SmA})$ phases, respectively. However, the $\mathrm{N}$ phase is not observed upon further lengthening of the alkoxy chain from ligand 1c $(n=12)$ to ligand 1e $(n=16)$. Instead, ligands 1c1e exhibit only enantiotropic SmA phase. The existence of SmA in ligands 1a-1e have earlier been proven by $\mathrm{X}$-ray diffraction. ${ }^{12}$

Optical observation shows that the whole homologous series of $\mathrm{Pd}(\mathrm{II})$ complexes $\mathbf{2 a - 2 e}$ exhibit SmA phase. Upon heating with the transition rate of

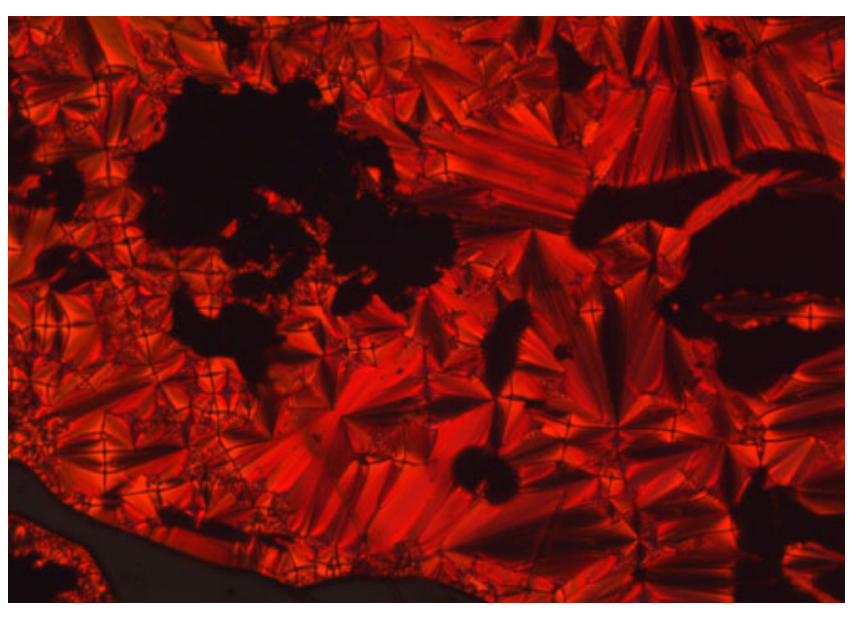

Figure 1. Photomicrograph showing the SmA phase with focal conic fan shape texture of complex $2 \mathrm{c}$ at $224.5^{\circ} \mathrm{C}$ upon heating. 
$5^{\circ} \mathrm{C} \min ^{-1}$, these complexes exhibit the SmA phase with focal conic fan-shaped texture as illustrated in figure 1. However, the transition is accompanied by partial decomposition and the continuous heating has led to isotropization.

Upon cooling with the same rate $\left(5^{\circ} \mathrm{C} \mathrm{min}^{-1}\right)$, the batonnets thus appeared in complex 2c (figure 2) coalesce to form the SmA phase (figure 3). It is also clearly shown from figure 3 that the focal conic fan-shaped texture filled with curved lines which exist over a large smectogenic temperature range but diminished upon crystallization. As in the Pd(II) complexes $\mathbf{2 a - 2 e}$, the presence of irregular shape of black spots observed in figures 1, 2 and 3 indicate fast decomposition. Hence,

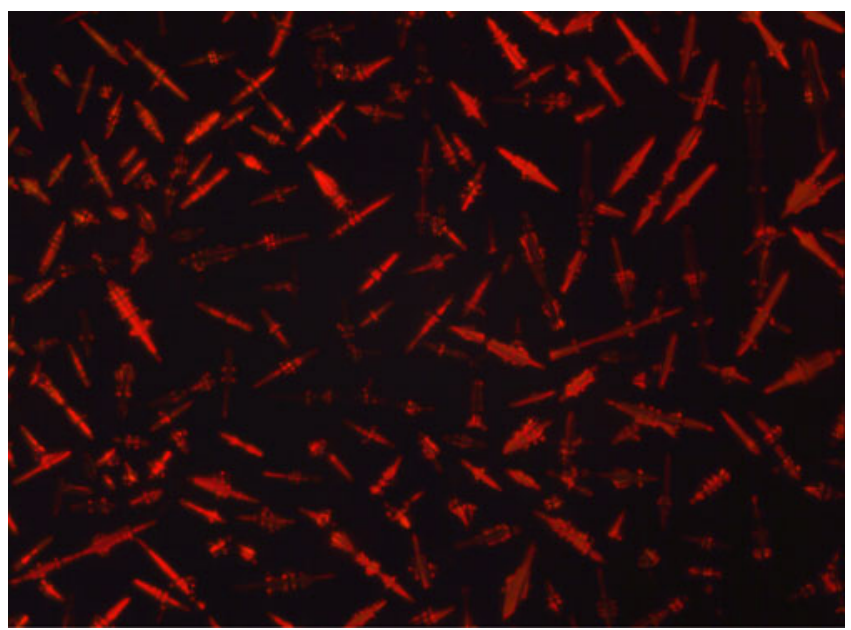

Figure 2. Photomicrograph showing the batonnets of complex $2 \mathbf{c}$ with the presence of arced lines at $242^{\circ} \mathrm{C}$ during the cooling process.

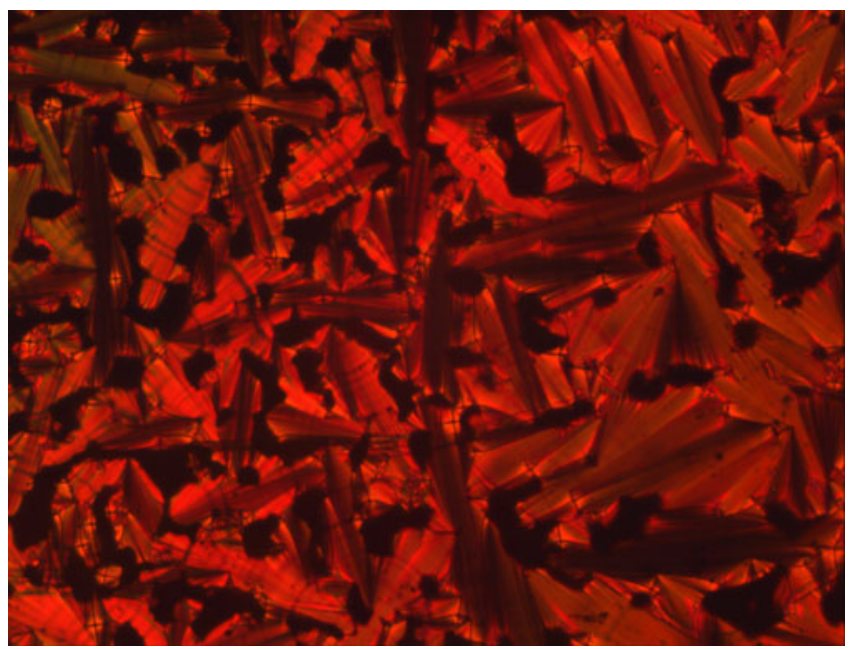

Figure 3. Photomicrograph showing the focal conic fan shape texture of complex $\mathbf{2 c}$ with the presence of arced lines on mesophase upon cooling. a complete photomicrograph attributed to the presence of SmA phase could not be observed. Besides, the fast decomposition behaviour of Pd(II) complexes has also affected the studies using X-ray diffraction and DSC.

A notable feature among these complexes $\mathbf{2 a}-\mathbf{2 e}$ is that the mesophases thus observed are reproducible upon heating and cooling processes even though these complexes are partially decomposed. However, the presence of arc in the SmA phase is only observed upon cooling process.

Figure 4 illustrates that the Pd complexes $2 \mathbf{a}(n=8)$ and $\mathbf{2} \mathbf{b}(n=10)$ exhibit only SmA phase in comparison to uncoordinated ligands exhibiting both $\mathrm{N}$ and smectic A phases. This could plausibly be due to the Pd(II) complexes which posses new coordination modes of $\mathrm{Pd}-\mathrm{O}$ and $\mathrm{Pd}-\mathrm{N}$ with greater polarity leading to the suppression of $\mathrm{N}$ phase. ${ }^{5,22}$ The other factor which enhances the smectogenicity of the complexes can be associated with the increase in the number of aromatic rings in the complexes which has resulted in the lateral interaction between the molecules. ${ }^{23}$

In addition, the correlation study upon heating process shows that the phase transition temperatures $(\mathrm{Cr}-$ SmA and SmA-I) of the Pd(II) complexes $\mathbf{2 a - 2 e}$ are relatively higher than those in $\mathbf{1 a - 1 e}$ (figure 4). This indicates that the introduction of $\mathrm{Pd}(\mathrm{II})$ increases the phase transition temperature of the corresponding ligands. This observation can be rationalized by the fact that the molecular weights as well as the number of interacting sites of $\mathbf{2 a - 2 e}$ are higher in comparison to the ligands. ${ }^{3}$ Further study upon these data also reveals that the transition temperature decreases when the number of carbon atom in the flexible alkoxy chain increases. This can be exemplified by the SmA-I

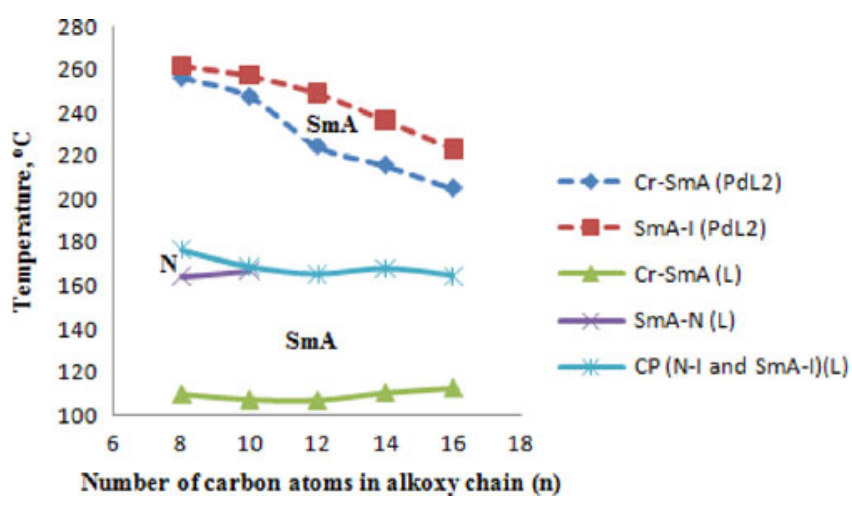

Figure 4. A set of plots of phase transition temperature upon heating versus the number of carbon atoms in alkoxy chain for the ligands 1a-1e, L (solid line) and their Pd(II) complexes, PdL2 (dotted line). Cr, crystal; SmA, Smectic A; $\mathrm{N}$, Nematic; I, Isotropic; $\mathrm{CP}$, Clearing point. 
temperature for $2 \mathbf{a}\left(261.9^{\circ} \mathrm{C}\right)$ which has decreased to $257.4^{\circ} \mathrm{C}, 249.2^{\circ} \mathrm{C}, 236.6^{\circ} \mathrm{C}$ and $223.4^{\circ} \mathrm{C}$ in $\mathbf{2 b}, \mathbf{2 c}, \mathbf{2 d}$ and $\mathbf{2 e}$, respectively.

3.3 The comparative study of existing Pd(II) complexes $2 a-2 e$ with earlier reported $\mathrm{Cu}(I I)$ and $\mathrm{Ni}($ II) complexes.

In order to rationalize the importance of different metal ion resulted from the liquid crystalline and thermal properties of 4-(4-alkoxy-2-hydroxybenzylideneamino)azobenzene ligands, the present $\mathrm{Pd}(\mathrm{II})$ complexes are compared with our earlier reported $\mathrm{Cu}(\mathrm{II})$ and $\mathrm{Ni}(\mathrm{II})$ complexes. ${ }^{12}$ Below is a summary of the mesophases for ligands 1a-1e with their corresponding $\mathrm{Cu}(\mathrm{II}), \mathrm{Pd}(\mathrm{II})$ and $\mathrm{Ni}(\mathrm{II})$ complexes. All the $\mathrm{Pd}(\mathrm{II})$ complexes $\mathbf{2 a - 2 e}$ show the SmA phase as observed in homologous $\mathrm{Cu}(\mathrm{II})$ complexes. ${ }^{12}$ However, the coordination of ligands 1a-1e to $\mathrm{Pd}(\mathrm{II})$ metal ion forms a less stable metal complexes which has been evident by the little decomposition of the complexes at melting temperature. In addition, there is obvious variation of the phase transition temperature in $\mathrm{Pd}(\mathrm{II})$ complexes as compared to $\mathrm{Cu}$ (II) and $\mathrm{Ni}$ (II) complexes (figure 5). Figure 5 shows that the $\mathrm{Pd}(\mathrm{II})$ complexes have an exceptionally high phase transition temperature. The whole homologous series of Pd(II) complexes have relatively higher transition temperatures of I-SmA as compared to those in $\mathrm{Cu}$ (II) complexes. Besides, the clearing temperatures for $\mathrm{Pd}(\mathrm{II})$ complexes are also significantly higher as compared to $\mathrm{Cu}$ (II) complexes especially for $\mathrm{Pd}(\mathrm{II})$ complexes with terminal alkoxy chain from $n=8$ to $n=12$. The differences may be due to the difference of the size of metal ion and the possibility of weak metal-metal intermolecular interaction between the complexes. ${ }^{24}$

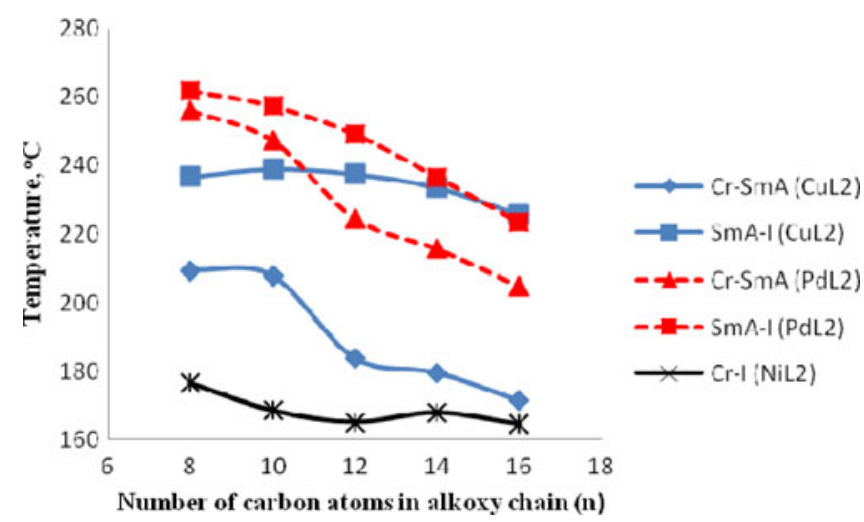

Figure 5. A set of plots of phase transition temperatures upon heating versus the number of carbon atoms in alkoxy chain for the $\mathrm{Cu}(\mathrm{II}), \mathrm{Ni}(\mathrm{II})$ and $\mathrm{Pd}(\mathrm{II})$ compexes. Cr, Crystal; SmA, Smectic A; I, Isotopic; CuL2,Cu(II) complexes; NiL2, Ni(II) complexes; PdL2, Pd(II) complexes.
The similar observation in mesomorphic region for $\mathrm{Cu}(\mathrm{II})$ and $\mathrm{Pd}(\mathrm{II})$ complexes suggests the similar coordination geometry between these two complexes. ${ }^{12,24}$ Thus, the Pd(II) complexes are suggested to have square planar geometry according to the common stereochemistry of this kind of compound. ${ }^{21}$

\section{$\underline{\text { Ligands 1a-1e }}$}

$\mathbf{1 a}$ and $\mathbf{1 b}(n=8$ and 10$)$

$\mathrm{Cr} \rightleftharpoons \mathrm{SmA} \rightleftharpoons \mathrm{N} \rightleftharpoons \mathrm{I}$

1c, 1d and 1e ( $n=12,14$ and 16)

$\mathrm{Cr} \rightleftharpoons \mathrm{SmA} \rightleftharpoons \mathrm{I}$

$\underline{\mathrm{Cu}(\mathrm{II}) \text { complexes }(n=8,10,12,14 \text { and } 16)}$

$\mathrm{Cr} \rightleftharpoons \mathrm{SmA} \rightleftharpoons \mathrm{I}$

$\underline{\mathrm{Ni}(\mathrm{II}) \text { complexes }(n=8,10,12,14 \text { and } 16)}$

$\mathrm{Cr} \rightleftharpoons \mathrm{I}$

$\underline{\text { Pd(II) complexes } \mathbf{2 a - 2 e}(n=8,10,12,14 \text { and 16) }}$

$\mathrm{Cr} \rightleftharpoons \mathrm{SmA} \rightleftharpoons \mathrm{I}$

\subsection{The comparative study of different core systems} on optical and thermal properties of Pd(II) complexes

The present $\mathrm{Pd}(\mathrm{II})$ complexes series derived from azobenzene-cored Schiff bases ligands 1a-1e are compared to the structurally related compounds reported by Yeap and co-workers in 2012 with general structure as shown below. ${ }^{25}$ Both series have almost similar molecular structure but with different types of cored systems. Thus, general rules for the effect of the chemical constitution in liquid crystalline and thermal properties can be deduced.

The general molecular structure of the two Pd(II) complexes are shown below where $\mathrm{Pd}(\mathrm{II})$ complexes 2a-2e consist of azobenzene-cored system whereas the $\operatorname{Pd}(\mathrm{II})$ complexes synthesized by Yeap and co-workers consist of benzothiazole-cored system. ${ }^{25}$

A comparison in term of optical or liquid crystalline properties between the azobenzene-cored Pd(II) complexes $\mathbf{2 a - 2 e}$ and benzothiazole-cored Pd(II) complexes reveals that the differences are pronounced. All the homologous members of $\mathrm{Pd}(\mathrm{II})$ complexes $\mathbf{2 a}-\mathbf{2 e}$ exhibit enantiotropic SmA phase whereas the DSC traces and optical observation of benzothiazole-cored 
Pd(II) complexes show that these complexes are nonliquid crystalline.

However, a comparison with regard to the thermal properties for both $\mathrm{Pd}(\mathrm{II})$ complexes show that all the benzothiazole-cored $\mathrm{Pd}(\mathrm{II})$ complexes undergo a considerable amount of decomposition right after the isotropic phase. Similarly, all the Pd(II) complexes $\mathbf{2 a -}$ 2e also exhibit thermal decomposition behaviour. But, these Pd(II) complexes just decompose slightly during the transition from crystal to SmA phase and the SmA phase is reproducible upon the subsequent heating and cooling processes.

The above observations show that azobenzene-cored system favours the mesophase formation and forms Pd(II) complexes $\mathbf{2 a - 2 e}$ which are more stable as compared to the benzothiazole-cored Pd(II) complexes that are fully decomposed. By substituting a core system with another one, the polarity, core length, rigidity and fractional residue volume are also altered. As a consequence, the differences in liquid crystalline and thermal behaviour of these two Pd(II) complexes can be distinguished.
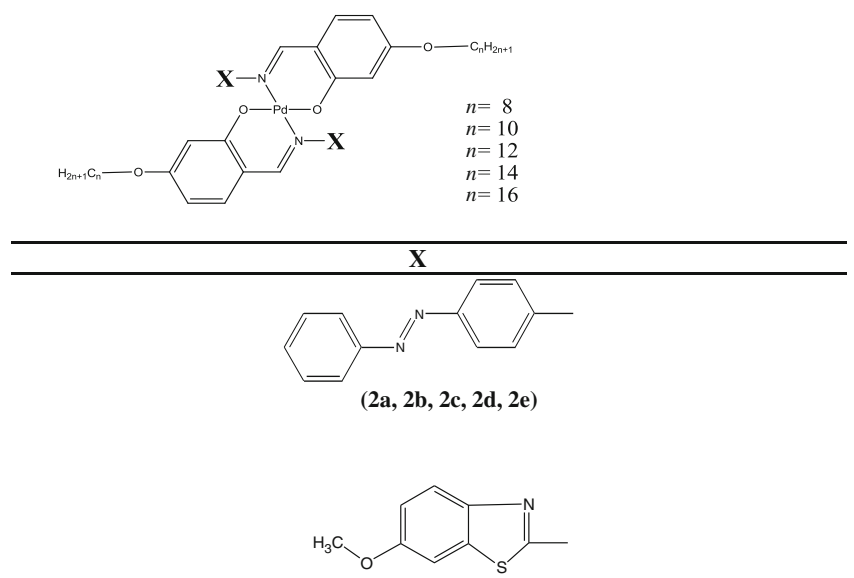

\section{Conclusion}

A series of $\mathrm{Pd}(\mathrm{II})$ complexes derived from 4-(4-alkoxy2-hydroxybenzylideneamino)azobenzene with various alkoxy groups of even parity $(n=8-16)$ were successfully synthesized and characterized. All ligands and related $\mathrm{Pd}(\mathrm{II})$ complexes are enantiotropic. The ligands with flexible alkoxy chain $n=8$ and $n=10$ exhibit $\mathrm{N}$ and SmA phases while all the $\mathrm{Pd}(\mathrm{II})$ complexes show the SmA phase with the presence of arched shape during the cooling process. The melting and clearing temperatures of Pd(II) complexes are significantly higher as compared to the uncoordinated ligands and it is decreased with increase in length of the alkoxy chain.
Besides, the Pd(II) complexes also have an exceptional higher phase transition temperatures as compared to $\mathrm{Cu}$ (II) and $\mathrm{Ni}$ (II) complexes. Comparative studies show that the azobenzene-cored Pd(II) complexes are more stable and favour the liquid crystalline formation as compared to the benzothiazole-cored Pd(II) complexes which are fully decomposed and non-mesogenic.

\section{Acknowledgements}

One of the authors (GYY) would like to thank Universiti Sains, Malaysia for the RU Grant No. 1001/ PKIMIA/811223.

\section{References}

1. Meyer E, Zucco C and Gallarlo H 1998 J. Mater. Chem. 81351

2. Thaker B T, Tander P K, Patel A S, Vyas C J, Jesani M S and Patel D M 2005 Indian J. Chem. 44A 265

3. Chae H W, Kadhin O N and Choi M G 2009 J. Liq. Cryst. 3653

4. Huang K P, Misra T K, Wang G R, Huang B Y and Liu C Y 2008 J. Chrom. A. 1215177

5. Suste A and Sunjic V 1996 Liq. Cryst. 20219

6. Gayathri C and Ramalingan A 2008 Spectrochim. Acta Mol. Biomol. Spectros. 69980

7. Xu T, Zhang C, Lin Y and Qi S 2008 Optical 119643

8. Saad A, Galstyan T V, Denariez-Roberge M M and Dumont M 1998 Optics Commun. 151235

9. Rezvani Z, Ahar L R, Nejati K and Seyedahnadian S M 2004 Acta Chim Slov. 51675

10. Rezvani Z, Divband B, Abbasi A R and Nejati K 2006 Polyhedron 251915

11. Nandiraju V S, Singha D, Das M and Paul M K 2002 Mol. Cryst. Liq. Cryst. $\mathbf{3 7 3} 105$

12. Yeap G Y, Heng B T, Kakeya M, Takeuchi D, Gorecka E and Ito M M 2011 J. Mol. Struct. 99968

13. Yeap G Y, Heng B T, Tanabe M and Takeuchi D 2011 Mol. Cryst. Liq. Cryst. 552217

14. Pucci D, Aiello I, Bellusci A, Callipari G, Crispini A and Ghedini M 2009 Mol. Cryst. Liq. Cryst. 500144

15. Mustafaa I M, Hapipaha M A, Abdullab M A and Warda T R 2009 Polyhedron 283993

16. Creavena B S, Duffa B, Egana D A, Kavanaghc K, Rosaird G, Thangellaa V R and Walsha M 2010 Inorg. Chim. Acta 3634048

17. Dey K, Sarkar S, Mukhopadhyay S, Malik A K, Biswas S and Bhaumik B B 2006 J. Coord. Chem. 111233

18. Marcos M, Serrano J L, Sierra T and Gimenez 1993 J. Chem. Mater. 51332

19. Yeap G Y, Ong C H, Takeuchi D, Kakeya M, Osakada K, Mahmood W A K, Atsuko O and Vill V 2008 J. Mol. Struct. $\mathbf{8 8 2} 18$

20. Blackburn O A, Coe B J, Fielden J, Helliwell M, McDouall J W and Hutchings M G 2010 Inorg. Chem. 499236

21. Hudson S A and Maitlis M 1993 Chem. Rev. 93861 
22. Plasseraud L, Cuervo L G, Guillon D, Fink G S, Deschenaux R, Bruce DW and Donnio B 2002 J. Mater. Chem. 122653

23. Karuna P, Reddy and Brown T R 1991 J. Mater. Chem. 1(5) 757
24. Chae H W, Kadhin O N and Choi M G 2009 J. Liq. Cryst. 3653

25. Yeap G Y, Heng B T, Faradiana N, Zulkifly R, Ito M M, Tanabe M M and Takeuchi D 2012 J. Mol. Struct. 10121 